\title{
Optimized design of slope roof space of the building based on thermal insulation performance analysis
}

\author{
Juan Zhao ${ }^{1, a}$,Yu Liu ${ }^{2, b}$, Jin Wang ${ }^{2, c}$,Yuanxin Zhao ${ }^{1, d}$ \\ ${ }^{1}$ School of Mechanics, Civil Engineering and Architecture, Northwestern Polytechnical \\ University, China \\ ${ }^{2}$ Northwestern Polytechnical University,127 Youyixi Road,Xi'an 710072,China \\ a 250515319@qq.com, ${ }^{\mathrm{b}}$ liuyu@nwpu.edu.cn, ${ }^{\mathrm{c}}$ 364203895@qq.com, ${ }^{\mathrm{d}}$ 809228273@qq.com
}

Keywords: NingQiang areas in southern Shanxi ; slope roof ; thermal insulation performance ; Designbuilder; Optimized design

Abstract: Through the research on the traditional houses and modern rural houses in the Ningqiang area of southern Shaanxi, it is found that the traditional rural houses generally use the storage space under the roof of the slope for summer heat insulation. However, the roof design is generally lack of climate adaptability, and the roof function is "Alienation", the lack of a combination of natural, ecological focus on the overall design. Contemporary rural housing in the early construction of the general use of the flat roof, the latter due to heat insulation, rainfall and other spontaneous demand in the original flat roof plus slope roof. In this paper, the thermal insulation space under the roof roof is selected from the aspects of the thermal insulation space height and the insulation space of the insulation space. And quantitative analysis, based on the improvement of thermal insulation performance, the quantitative method for the slope roof insulation design to provide the necessary data support, summed up the southern Shaanxi Ningqiang slope roof space optimization design strategy. It is of practical significance to the space reconstruction of existing buildings and the spatial design of new farm houses.

\section{Background}

Shaanxi Ningqiang belongs to the region of hot summer and cold winter climate regionalization in China. The region belongs to the non heating area stipulated by the state, and has always been the key area of residential heat insulation. Due to the high altitude of the sun in summer, combined with solar radiation and outdoor temperature, there is much more heat from the roof to the interior than from the wall. The roof as an enclosure structure caused greater heat consumption than any external walls or floor of the building. Therefore, improving the thermal insulation performance of roof is especially important to improve the ability of resisting outdoor heat in summer. This is also an important measure to reduce energy consumption of air-conditioning and improve indoor thermal environment in summer.

Found in a lot of field research in the area of traditional dwellings in Ningqiang, mostly through traditional bamboo and other materials separated the room under the roof and the living space, the space below the roof and above the living space called " heat insulation". In traditional dwellings, the function of "heat insulation" is obvious. In addition to the usual storage and drying function, it also plays an active role in improving the indoor thermal environment in summer. But most of the existing rural new residential roof has instead of the traditional form of slope, the changes of indoor temperature with flat roofs in summer are much more obvious than those on sloping roofs. Due to the need for thermal insulation and drainage, flat roofs were transformed into sloping roofs 
spontaneously. In addition, in the new sloping roof house, the handling of the space under the traditional sloping roof has changed (Figures 1,2), the "heat insulation" under the traditional sloping roof has disappeared.In terms of thermal conductivity of materials, the air at room temperature thermal conductivity is $\left.0.024 \mathrm{~W} /\left(\mathrm{m}^{2} \cdot \mathrm{K}\right)\right)$, significantly lower than the commonly used thermal conductivity. The advantage of air as heat insulation medium is obvious. Therefore, under the premise of the increasing energy consumption of modern buildings, we should fully tap the possibility and necessity of this traditional ecological wisdom.

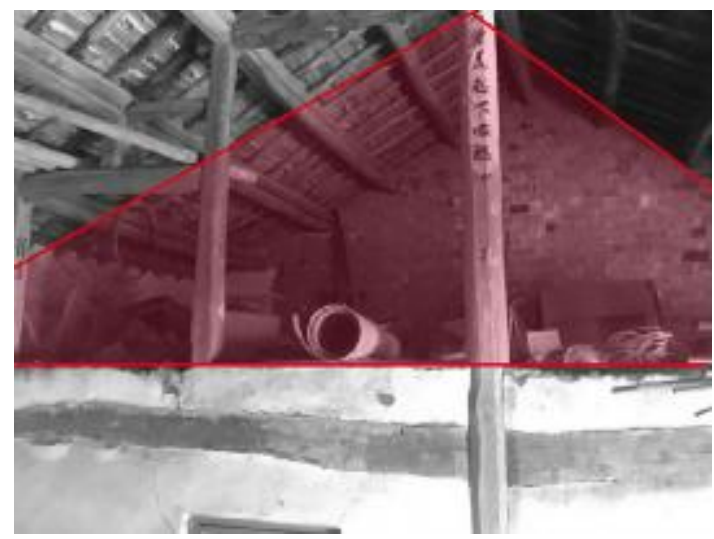

Figure1. the slope of the roof insulation space under the traditional rural housing

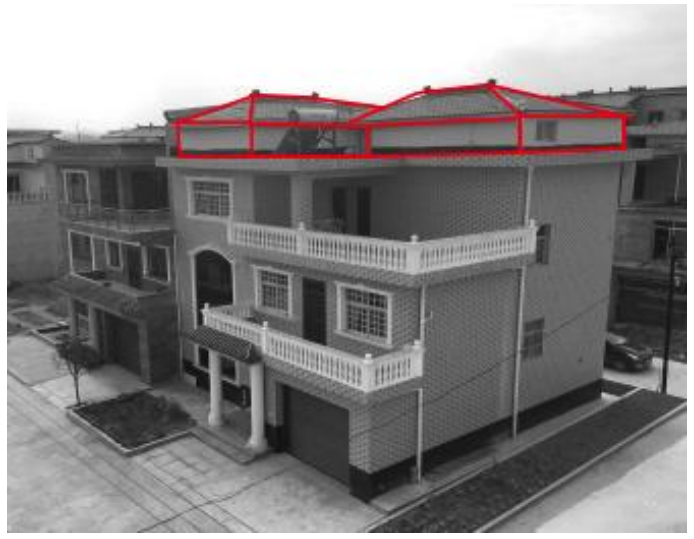

Figure2. the modern residential flat roof insulation layer added

\section{The status quo analysis of space construction of Ningqiang area under the roof slope}

The annual average temperature of Ningqiang from 1957 to 2007 is 12.9 degrees, the average maximum temperature is 18 degrees, and the average minimum temperature is 9.2 degrees. The average temperature showed a slight upward trend. The average temperature is relatively low from 1957 to early 60 s.From the beginning of 60 s to the end of 70 s the average temperature is relatively high. The average temperature from 1980 to mid 90s began relatively low. After mid 90s, temperature entering a relatively warm period, temperature rises obviously.

The above chart data shows that the summer maximum temperatures of Ningqiang area over the years is around 30 floating, in recent years, the summer maximum temperature reached above 30 , and there is a trend of rising. According to meteorological data, the extreme high temperature in 2015 is as high as 35.4 degrees centigrade, the demand for heat insulation in summer is remarkable. (Figs. 4, Table1)

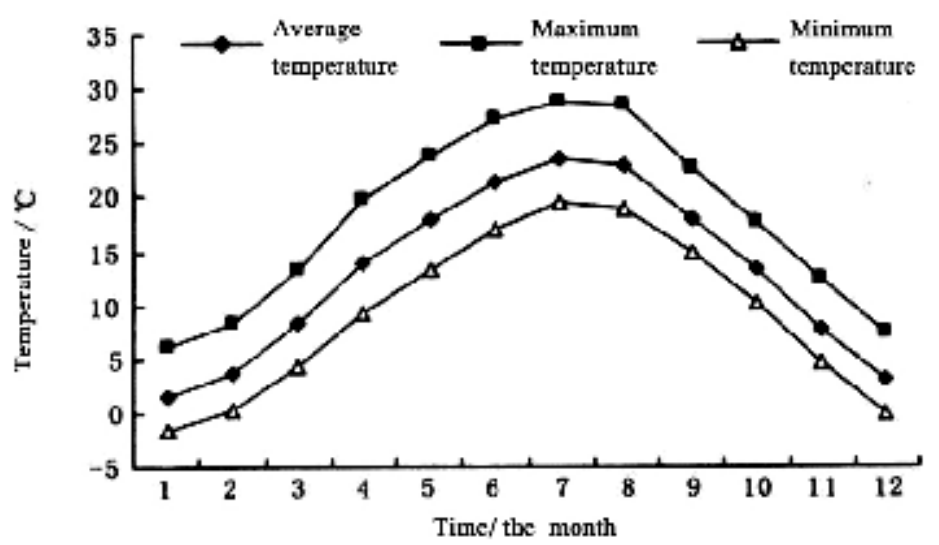

Fig.3 The temperature of Ningqiang 


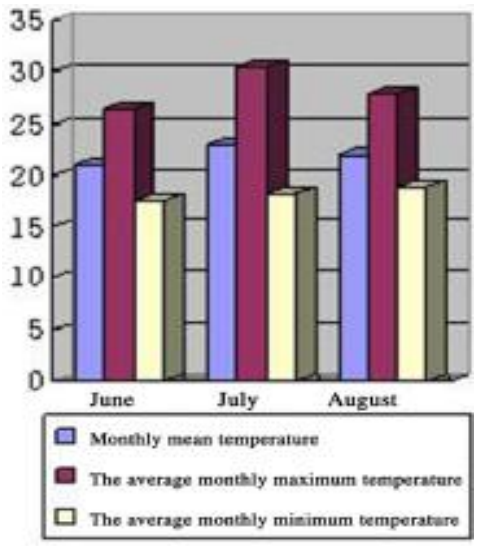

Fig. 4 The temperature changes from June 2015 to August in Ningqiang County

Table1 Ningqiang County 2015 year meteorological data

\begin{tabular}{|c|c|c|c|}
\hline Year & $\begin{array}{c}\text { Annual average } \\
\text { temperature }\end{array}$ & $\begin{array}{c}\text { Annual average } \\
\text { minimum temperature }\end{array}$ & $\begin{array}{c}\text { Annual extreme } \\
\text { maximum temperature }\end{array}$ \\
\hline 2015 & $13.3^{\circ} \mathrm{C}$ & $19.0^{\circ} \mathrm{C}$ & $35.4^{\circ} \mathrm{C}$ \\
\hline
\end{tabular}

Most of traditional farming curtilage in Ningqiang use slope roof. The triangular space under the slope roof has certain thermal insulation performance. The general practice in traditional farming curtilage is to distinguish the insulation space and living space under the roof through horizontal separation.

l. The insulation space is usuany useu to store ueons anu lovu, nergnt is hoanng in a certann range depending on whether someone stands. the living space is often used as a living room or bedroom. (Figure 5, 6) Local people usually add a wooden structure slope roof on the brick structure flat roof, space under the slope roof used for storage, if height allowed, it can also be used as a bedroom. This kind of "heat insulation" improves the insulation performance of to a certain extent, but the integrity of the space under the slope roof is not broken, and the fluidity of the air will greatly reduce the comfort of the heat insulation. As a result, can we improve the thermal insulation performance and the comfort of the heat insulation added on the flat roof by changing the treatment of the space under the slope roof.

\section{Study On The Performance Of Heat Insulation In Building Space Under The Roof Slope Of Ningqiang Area}

To create a good thermal comfort and good indoor space, it is an important part to choose the right space. The construction of spatial form mainly consists of two aspects: spatial scale and sectional form. The appropriate spatial scale should grasp the spatial function, form and performance of the three dimensions to balance the spatial parameters of the building and the appropriate space proportion is the key to satisfy the space physical performance. As far as a single variable is concerned, the height of the space under the sloping roof directly determines the medium quality in the space, and has a certain effecton the heat insulation performance. In terms of the sectional shape of the space, the separation interface between the heat insulation space and the lower use space is closed or semi closed, and has some influence on the heat insulation performance. The closed or semi-closed interface is most widely used in practice. It allows the space between the 
slope roof and the living room to be separated from each other. It can be effectively insulated by a specific opening. (Fig.5)
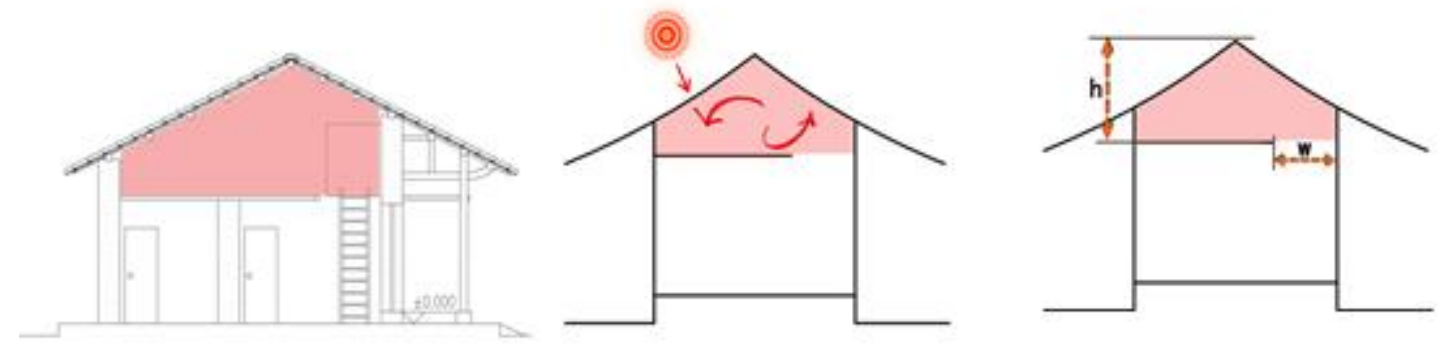

Fig. 5 the space between the slope roof and the living room to be separated from each other.

In the software modeling, the ideal model of this area is set up according to the typical pattern of plane and space form, enclosure structure and material of rural residence in this area .(Fig. 6 andFig. 7) The plane selected the local typical of the three room form , the width and depth of $5100 \mathrm{~mm}$ on both sides of the bedroom, the width and depth of $3600 \mathrm{~mm}$ and $5100 \mathrm{~mm}$ respectively.Remain the location, size, roof slope and other factors of the door and window unchanged. The body of the ideal model adopts the local common brick concrete structure, and the roof is paved with glazed tile.

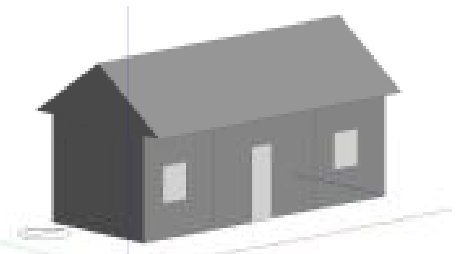

Fig. 6 Ideal model axonometric drawing

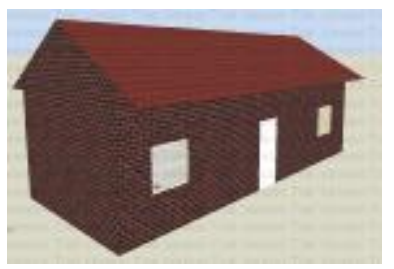

Fig. 7 Ideal model material performance map

Table 2 The influence of the height of heat insulation space on the room temperature

\begin{tabular}{|l|l|l|l|l|l|l|l|l|}
\hline Height $(\mathrm{mm})$ & 0 & 1500 & 1800 & 2100 & 2400 & 2700 & 3000 & 3300 \\
\hline $\begin{array}{l}\text { Radiation } \\
\text { temperatu }\left({ }^{\circ} \mathrm{C}\right)\end{array}$ & 19.31 & 18.67 & 18.40 & 18.21 & 17.76 & 18.22 & 18.70 & 19.43 \\
\hline
\end{tabular}

Under the control variables, change the height of the insulated space under the sloping roof. The range of adjustment is $1500-3300 \mathrm{~mm}$, and the difference is $300 \mathrm{~mm}$. Set the air temperature to 22 degrees centigrade. Through the Designbuilder software energy consumption simulation, draw the table 2 and the Fig. 8 and the Fig. 9. 


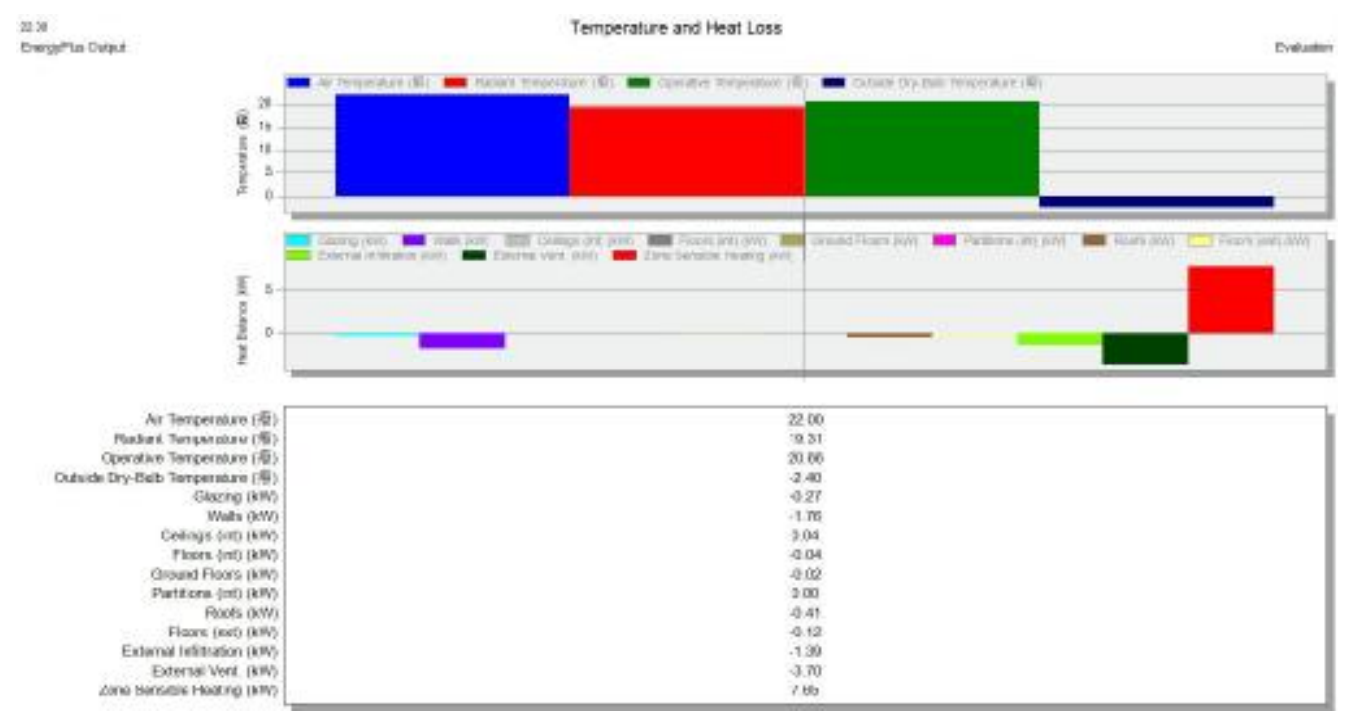

Figure 8 Temperature and heat loss under a sloping roof without insulation
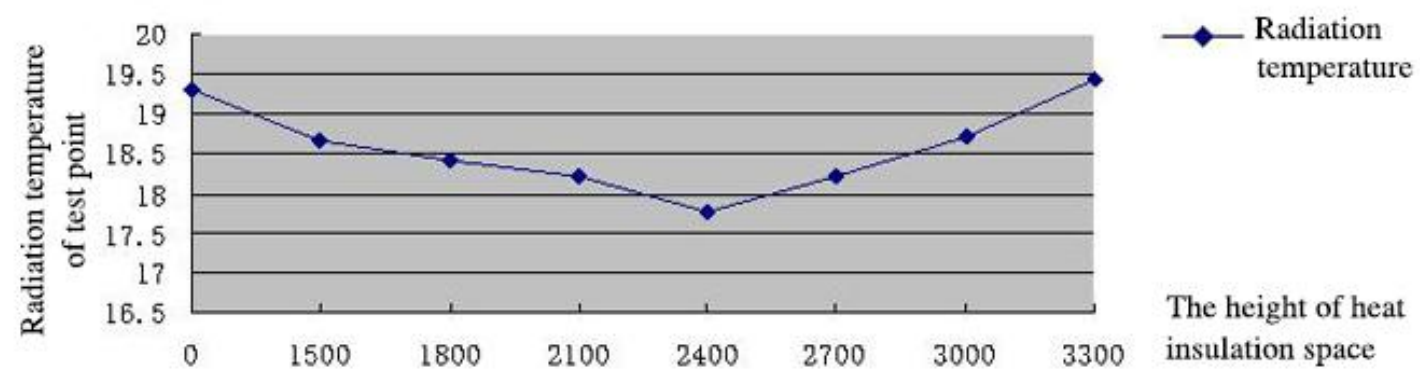

Figure 9 The influence of the height of the insulated space on the room temperature

The data above shows: under the same plane and structure,and the slope of the roof is not set insulation space, the radiation temperature of the room will be higher than that of setting up the heat insulation space. With the increase of the insulation space, the insulation effect will be improved.According to the basic principle of slope roof insulation: isolation air layer increases the average slope under the heat resistance of the roof, so that the internal and external heat exchange room is difficult to carry out. In the summer, the sun is blocked and the heat is transmitted to the interior., and in winter, the heat of the house is lost through the roof, Improving the comfort of the room,it is a more practical form of roof.But when the insulation space height reaches to $2400 \mathrm{~mm}$, the insulation efficiency decreases. Rational analysis, This is because the air layer makes the space below the slope roof become a buffer zone between the external environment and the use of space. Moreover, the increase of the average thermal resistance brought by the air layer makes it difficult for the outside heat to enter the space indoor, thereby improving the comfort of the room.Thus, when the height of the heat insulation space at the slope roof is about $2400 \mathrm{~mm}$, can effectively improve the thermal comfort and living quality of the room.

Secondly, the size and structure of the ideal model are controlled by the method of control variables, and the opening dimension of the separation interface is adjusted. Because the opening length is equidistant from the room width, the width is changed. According to ergonomic and usage habits, the opening size range is selected at $600 \mathrm{~mm}-1200 \mathrm{~mm}$, the difference is $100 \mathrm{~mm}$. Through the Designbuilder software energy consumption simulation, draw the Table 3 and the Figure 10. 
Table 3 Influence of opening size of heat insulation space on room temperature

\begin{tabular}{|l|l|l|l|l|l|l|l|l|}
\hline Opening width $(\mathrm{mm})$ & 0 & 600 & 700 & 800 & 900 & 1000 & 1100 & 1200 \\
\hline $\begin{array}{l}\text { Radiation } \\
\text { temperature }\left({ }^{\circ} \mathrm{C}\right)\end{array}$ & 17.42 & 18.21 & 18.40 & 18.63 & 18.81 & 18.98 & 19.12 & 19.28 \\
\hline
\end{tabular}

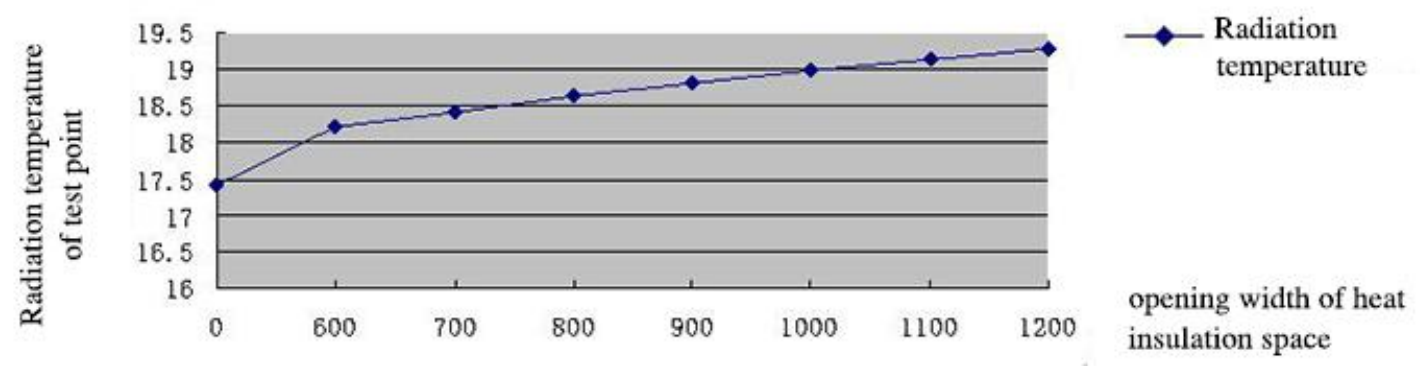

Figure10 Influence of opening width of heat insulation space on space temperature of room

The data from the above table show that the separation of heat insulation space and living room space is the best under the condition of full closure (opening width of 0). As the opening size increases, the higher the temperature of the room, that is, the reduction of heat insulation effect.Since full enclosed insulation affects normal use, openings are necessary. The contradiction between the efficiency of heat insulation and the use function can be solved by movable openings. Design an opening into a closed form. When necessary, the opening can be opened to let people or articles pass through, and at the same time, the opening can also play the role of wind drawing and dehumidification.

From the two sets of simulated data, it can be clearly seen that the space under the sloping roof does have an insulation effect, which is the advantage of flat roofs. In a certain height range, it can make the best effect. Besides, the movable opening can ensure the heat insulation space and the use function and achieve the best heat insulation effect at the same time.On the thinking of deepening, you can consider using a double roof air layer: the upper roof under the most intense environmental impact and caused direct impacts on the air layer, the lower roof is only between the air and the heat exchange layer, in a relatively stable environment, more conducive to improving the room comfort design; design principle of air interlayer can be combined with the ventilation of the roof can be opened and closed device, It can take away the heat from the air in the summer and prevent the heat from escaping in the winter.

\section{Conclusion}

Through the investigation on the present situation of rural residential roof in Ningqiang area analysis and the simulation of thermal insulation space under sloping roof, the optimum design strategy of heat insulation space dimension of residential sloping roof under suitable summer climate characteristics is obtained. But there are many other factors affecting the performance of space insulation.In the design practice, it should be combined with the climatic conditions in Ningqiang area, considering the material, structure and other factors, such as the sunshine, rainfall, ventilation and new materials and combination of old and new materials, so as to improve the comfort of the building. 


\section{Acknowledgments}

The research of this paper was sponsored by the Seed Foundation of Innovation and Creation for Graduate Students in Northwestern Nontechnical University (Z2017122), 2016 International Science and Technology Collaboration and Communication Program of Shanxi Province (No.2016KW-031), and the 12th Five-Year Science and Technology Support Program of China (2015BAL03B04-2).

\section{References}

[1] Peng Zhou . The Design Strategies Research on the Climate Adaptability of Residential Roof in Hot-summer and Cold-winter Zone [D].Huazhong University of Science and Technology ,2004. [2] Chenchen $\mathrm{Wu}$. The method for determining the heat transfer performance of sloping roofs on residential building [D].SouthChina University of Technology,2012.

[3] Min Ji . Hot summer and cold winter in residential buildings in the roof structure energy-saving and environmental design[D].Hunan University,2008.

[4] Bojić M.L., Milovanović M., Lovedaya D. Thermal behavior of a building with a slanted roof [J]. Energy and buildings, 1997. 